\title{
Spindle Cell Oncocytoma of the Adenohypophysis With Marked Hypervascularity -Case Report-
}

\author{
Hironori FujISAWA, ${ }^{1}$ Yasuo TOHMA, ${ }^{1}$ Naoki MURAMATSU, ${ }^{1}$ \\ Shinya KIDA, ${ }^{1}$ Yasuharu KAIZAKI, ${ }^{2}$ and Hiroyasu TAMAMURA ${ }^{3}$ \\ Departments of ${ }^{1}$ Neurosurgery, ${ }^{2}$ Clinical Pathology, and \\ ${ }^{3}$ Nuclear Medicine, Fukui Prefectural Hospital, Fukui, Fukui
}

\begin{abstract}
A 68-year-old male presented with a very rare case of spindle cell oncocytoma (SCO), a recently identified very rare neoplasm of the anterior pituitary, manifesting as panhypopituitarism and visual field defect. The pituitary tumor with suprasellar extension was only partially resected via transsphenoidal surgery because of the tumor consistency and bleeding. Histological diagnosis was consistent with schwannoma. The tumor regrew and angiography revealed hypervascularity, so a transcranial approach was employed for the re-operation which only achieved partial resection because of intraoperative extensive bleeding. The tumor cells showed similar histological and immunohistochemical profiles to the previous specimen, but electron microscopy demonstrated that cytoplasm abundantly filled with mitochondria. The final diagnosis of SCO was established and the patient received postoperative conventional radiation therapy of $50 \mathrm{~Gy}$. Only 15 cases of SCO have been reported, and the diagnosis was mistaken in many cases as schwannoma, oncocytic pituitary adenoma, or craniopharyngioma, and multiple surgeries followed by radiation therapy were required.
\end{abstract}

Key words: spindle cell oncocytoma, hypervascularity, angiography, electron microscopy, mitochondria

Received June 21, 2011; Accepted August 29, 2011 


\section{Introduction}

Spindle cell oncocytoma (SCO) is a rare non-endocrine neoplasm of the pituitary adenohypophysis originally described in $2002^{11)}$ and classified as a distinct entity in the World Health Organization (WHO) 2007 Classification. ${ }^{5)}$ SCO grows slowly and follows a benign clinical course corresponding to WHO grade 1 . To date, only 15 cases have been reported..$^{1-4,8,9,11,12)}$ The clinical and radiological features of SCO are nonspecific and indistinguishable from those of non-functioning macroadenoma, but its histological profile is quite different; the tumor consists of interwoven fascicles of spindle cells exhibiting abundant eosinophilic cytoplasm, rare mitosis, but no necrosis. The tumor cells show immunoreactivity for vimentin, S-100 protein, and epithelial membrane antigen (EMA), and the cytoplasm contains abundant mitochondria.

We report a case of SCO that developed in a previously healthy elderly male. The tumor was partially resected by transsphenoidal surgery and a subsequent transcranial approach because of the consistency and intraoperative extensive bleeding, followed by postoperative radiation therapy.

\section{Case Report}

A 68-year-old male was admitted in 2008 because of unsteady gait, general malaise, and depression persisting for 2 years. Neurological examination revealed panhypopituitarism and irregularly outlined visual field defects. Magnetic resonance (MR) imaging found an intrasellar mass with suprasellar extension (Fig. 1). Under a diagnosis of non-functioning macroadenoma, transnasaltranssphenoidal surgery was performed without angiography. However, the tumor was elastic and hypervascular, so the surgery achieved only partial resection. Postoperative course was uneventful and visual field normalized. Histological examination showed interlacing fascicles of spindle to epitheloid cells with an eosinophilic, granular cytoplasm (Fig. 2A). Minimal nuclear atypia and lymphocytic infiltration were also observed, whereas adenomatous figure, necrosis, and mitosis were absent.
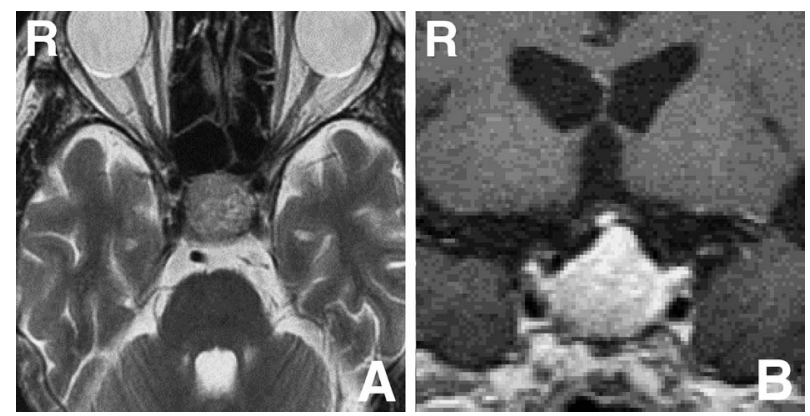

Fig. 1 Preoperative axial $\mathrm{T}_{2}$-weighted magnetic resonance image (A) and coronal $T_{1}$-weighted image with gadolinium (B) showing a solid and noninvasive tumor occupying the sella turcica with mild suprasellar extension, enhanced homogeneously with gadolinium administration.
The tumor cells showed immunoreactivity for vimentin, S-100 protein, and EMA (Fig. 2B, C), but not for pituitary hormones, chromogranin, synaptophysin, glial fibrillary acidic protein (GFAP), cytokeratin, and CD68. Periodic acid-Schiff staining was also negative. MIB-1 index was 3\% (Fig. 2D). Ultrastructural study was not performed at that time and the tumor was diagnosed as a schwannoma.

One and a half years after the first resection, the tumor regrew and the patient noticed decreased visual acuity and bitemporal hemianopsia. Angiography was performed prior to the second surgery. The tumor was extensively fed by the bilateral internal carotid arteries and draining veins were seen in the arterial phase (Fig. 3A).

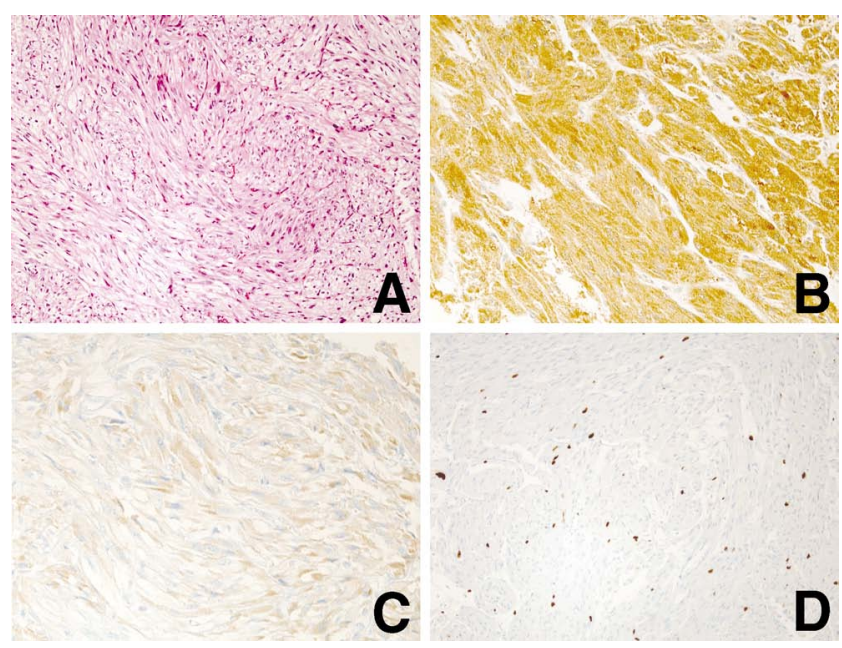

Fig. 2 Photomicrographs of the first surgical specimen showing interlacing fascicles of spindle to epitheloid cells with eosinophilic and granular cytoplasm. Nuclear atypia is minimal and mitosis and necrosis are absent (A: hematoxylin and eosin stain, original magnification $\times 100$ ). The tumor was intensely positive for S-100 protein (B: original magnification $\times 200$ ) and the cytoplasm and cell membrane were also immunoreactive for epithelial membrane antigen (C: original magnification $\times$ 400). MIB-1 index was $3 \%$ (D: original magnification $\times 100$ ).


Fig. 3 Right carotid angiogram before the second surgery showing the tumor extensively fed by the internal carotid artery in the arterial to venous phases (A, oblique view). Retrospectively, magnetic resonance angiogram at presentation is consistent with the angiogram, showing numerous and faint intratumoral vessels (B, arrow). 


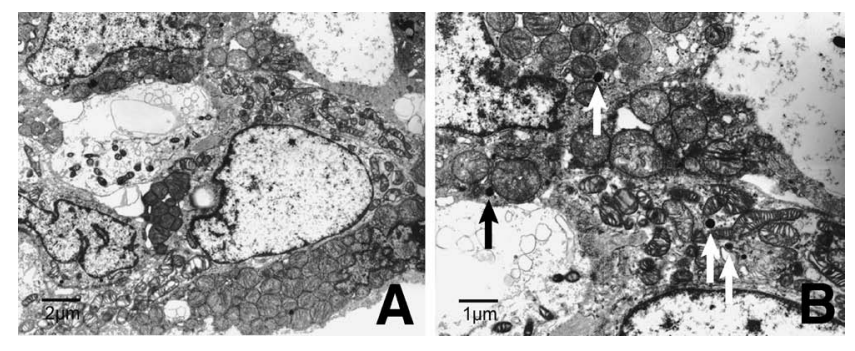

Fig. 4 Electron micrographs of the second surgical specimen. Cytoplasm of the tumor cells is filled with abundant swollen mitochondria (A: bar $=2 \mu \mathrm{m}$ ). A few neurosecretory granules (size range $130-270 \mathrm{~nm}$ ) are occasionally seen (arrows) (B: bar $=1 \mu \mathrm{m})$.

Consistent with these findings, retrospective careful review of the preoperative MR angiography confirmed the presence of numerous but faint intratumoral vessels (Fig. $3 \mathrm{~B}$ ). Because of the previous diagnosis of schwannoma and the tumor hypervascularity, a second surgery was attempted via the right pterional approach. The tumor was again elastic to firm and bleeding was extensive, so only partial resection was performed, decompressing the optic chiasm and nerves. Intraoperative blood loss was $900 \mathrm{ml}$. Postoperatively, transient diabetes insipidus persisted for three weeks. Visual field remained unchanged but acuity of the right eye deteriorated. Conventional radiation therapy of $50 \mathrm{~Gy}$ in 25 fractions was prescribed for the residual tumor. Histological evaluation revealed similar morphology and immunohistochemical profiles to the previous specimen. Ultrastructural examination showed the spindle or polygonal tumor cells were filled with abundant rods and swollen mitochondria (Fig. 4A). Only a few small secretory granules $(130-270 \mathrm{~nm})$ were dispersed in the cytoplasm (Fig. 4B). Junctional complexes were occasionally seen but the surrounding basement membrane was absent. On the basis of these findings, the final diagnosis was SCO.

\section{Discussion}

The 16 reported cases of SCO including the present case are described in Table 1. The estimated incidence is $0.1-0.4 \%$ of all sellar region tumors ${ }^{9,11)}$ with equal sex distribution. Age at presentation ranged between 26 and 76 years (mean 60 years). Immunohistochemical reactivity for vimentin, S-100 protein, and EMA, and abundant mitochondria and junctional complexes on electron microscopy are pathognomonic for SCO. Based on these similarities, SCO may be derived from folliculostellate cells, the presumed stem cell of the pituitary adenohypophysis ${ }^{7)}$ but the true cellular origin is still unknown. The proliferation rate is generally low, but high MIB-1 indices (18-20\%) were reported in recurrent tumors. ${ }^{8)}$ Although the MIB-1 indices of the primary tumors are not known, the proliferation rate of SCO is likely to increase according to recurrence. These findings show that initial surgery and postoperative adjuvant therapy are critical. No metastasis has been reported inside or outside the brain.

Despite these characteristic histological and immunohistochemical profiles, SCO is easily misdiagnosed if the evaluation is incomplete, without ultrastructural study. In fact, among the 16 cases, seven were misdiagnosed (Table 1): four were misdiagnosed as schwannoma because of the similar spindle morphology and the intense immunoreactivity for S-100 protein, and one was misdiagnosed as craniopharyngioma because of multiple spontaneous intratumoral hemorrhages. The remaining two were misdiagnosed as oncocytic pituitary adenoma (oncocytoma). Other differential diagnoses include pituicytoma, granular cell tumor, fibrous meningioma, and solitary fibrous tumor. Pituitary schwannomas are rarely reported, ${ }^{10)}$ but should be re-evaluated by both immunohistochemistry and electron microscopy for unrecognized SCO.

Ultrastructural findings of abundant mitochondria in the cytoplasm and junctional complexes at the cell border are the specific characteristics of SCO. However, whether or not SCO contains neurosecretory granules remains controversial. The original description stated that ${ }^{11)}$ SCO did not contain these structures, but otherwise was demonstrated ${ }^{3,8)}$ Interestingly, the granules were found in the primary tumor but not in recurrent tumor in one case. ${ }^{8)}$ Similarly, only a few granules were detected in our case. These findings suggest that the detection of a few neurosecretory granules does not exclude the diagnosis of SCO.

Correct preoperative diagnosis is usually difficult, so transsphenoidal resection should be attempted first. However, local tumor control cannot be achieved by a single procedure as SCO is often firm and hypervascular. Multiple approaches, including transcranial resection and postoperative radiation therapy, are needed for local tumor control. Because of the firm consistency and the rich vascularity, the transsphenoidal procedure was complicated in seven cases (Cases 6, 8, 9, 11, 14, 15, and 16 in Table 1) and two cases required further transcranial resection (Cases 8 and 16). Although the usefulness and indication are not yet established, postoperative radiation therapy was employed in five cases with a dose between 50 and $54 \mathrm{~Gy}$. In four cases, disease remained stable for as long as 7 years, and in the remaining one case, no followup results were available. In most cases, local control was achieved in the short term, but tumor recurrence was noted in the longer follow-up period (with a maximum interval of 13 years) despite gross total resection (Case 14). ${ }^{1)}$ Recurrence took place not only in cases with high MIB-1 indices but also in cases with low indices (Case 15).4) Together, these findings suggest that patients with SCO should be carefully followed up for long periods and that it may be premature to assign this tumor to only WHO grade 1. ${ }^{1)}$

No angiographic description of SCO has been reported. In five cases (Cases 9, 11, 14, 15, and 16), the tumor was judged to be hypervascular based on preoperative MR imaging in one case (Case 14) and intraoperative extensive bleeding in four cases (Cases 9, 11, 15, and 16). In most cases, the preoperative diagnosis was a non-functioning adenoma and consequently angiography was not per- 


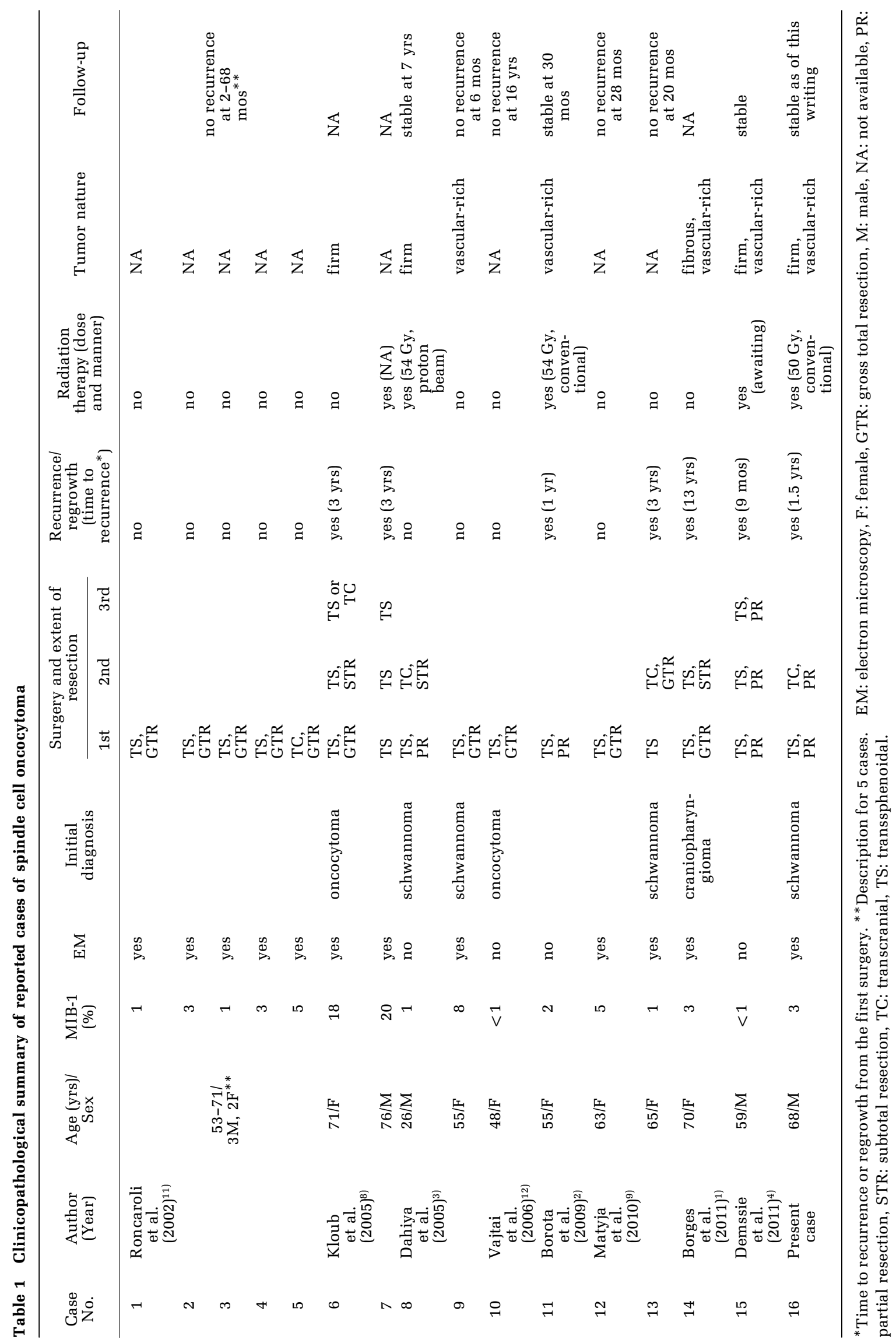


formed before surgery. Hypervascularity is potentially characteristic to SCO, but we also should be aware of pituicytoma, a rare glioma developing in the neurohypophysis. This tumor shows not only similar morphology to SCO but also hypervascularity, and occasionally induces intraoperative massive bleeding. ${ }^{1,6)}$ Pituicytoma normally shows immunoreactivity for GFAP and lacks mitochondrial proliferation, so immunohistochemistry and electron microscopy are essential for the distinction.

The present case of SCO was initially misdiagnosed as schwannoma. The tumor had firm consistency and hypervascularity, so was partially resected and treated with conventional radiation therapy. If hypervascularity is suspected on preoperative MR angiography, direct angiography is required and pituitary surgeons should prepare for massive intraoperative bleeding.

\section{References}

1) Borges MT, Lillehei KO, Kleinschmidt-DeMasters BK: Spindle cell oncocytoma with late recurrence and unique neuroimaging characteristics due to recurrent subclinical intratumoral bleeding. J Neurooncol 101: 145-154, 2011

2) Borota OC, Scheithauer BW, Fougner SL, Hald JK, RammPettersen J, Bollerslev J: Spindle cell oncocytoma of the adenohypophysis: report of a case with marked cellular atypia and recurrence despite adjuvant treatment. Clin Neuropathol 28: 91-95, 2009

3) Dahiya S, Sarkar C, Hedley-Whyte ET, Sharma MC, Zervas NT, Sridhar E, Louis DN: Spindle cell oncocytoma of the adenohypophysis: report of two cases. Acta Neuropathol 110: 97-99, 2005

4) Demssie YN, Joseph J, Dawson T, Roberts G, de Carpentier J, Howell S: Recurrent spindle cell oncocytoma of the pituitary, a case report and review of literature. Pituitary 14:
367-370, 2011

5) Fuller GN, Scheithauer BW, Roncaroli F, Wesseling P: Spindle cell oncocytoma of the adenohypophysis, in Louis DN, Ohgaki H, Wiestler OD, Cavenee WK (eds): WHO Classification of Tumours of the Central Nervous System. Lyon, IARC Press, 2007, pp 245-246

6) Gibbs WN, Monuki ES, Linskey ME, Hasso AN: Pituicytoma: diagnostic features on selective carotid angiography and MR imaging. AJNR Am J Neuroradiol 27: 1639-1642, 2006

7) Horvath E, Kovacs K: Folliculo-stellate cells of the human pituitary: a type of adult stem cell? Ultrastruct Pathol 26: 219-228, 2002

8) Kloub O, Perry A, Tu PH, Lipper M, Lopes MBS: Spindle cell oncocytoma of the adenohypophysis. Report of two recurrent cases. Am J Surg Pathol 29: 247-253, 2005

9) Matyja E, Maksymowicz M, Grajkowaska W, Olszawski W, Zielinski G, Bonicki W: Spindle cell oncocytoma of the adenohypophysis-a clinicopathological and ultrastructural study of two cases. Folia Neuropathol 48: 175-184, 2010

10) Park HW, Jung S, Jung TY, Moon KS: Intra-suprasellar schwannoma originating from the diaphragma sellae. $J$ Korean Neurosurg Soc 45: 375-377, 2009

11) Roncaroli F, Scheithauer BW, Cenacchi G, Horvath E, Kovacs K, Lloyd RV, Abell-Aleff P, Santi M, Yates AJ: 'Spindle cell oncocytoma' of the adenohypophysis: a tumor of folliculostellate cells? Am J Surg Pathol 26: 1048-1055, 2002

12) Vajtai I, Sahli R, Kappeler A: Spindle cell oncocytoma of the adenohypophysis: Report of a case with a 16-year follow-up. Pathol Res Pract 202: 745-750, 2006

Address reprint requests to: Hironori Fujisawa, MD, Department of Neurosurgery, Fukui Prefectural Hospital, 2-8-1 Yotsui, Fukui 910-8526, Japan.

e-mail: hfujisawa@room.ocn.ne.jp 